\title{
Modeling and Optimization of Wafer-level Spatial Uniformity with the Use of Rational Subgrouping
}

\author{
Ruey-Shan Guo \\ Department of Industrial \\ Management \\ National Taiwan University
}

\author{
Argon Chen \\ Graduate Institute of \\ Industrial Engineering \\ National Taiwan University
}

\author{
Cheewee Liu \\ Department of Electrical \\ Engineering \\ National Taiwan University
}

\author{
A. Lin and M. Lan \\ Graduate Institute of \\ Industrial Engineering \\ National Taiwan University
}

Abstract - The goal of this paper is to present the rational subgrouping methodology for modeling and optimization of the wafer-level spatial uniformity. In particular, a singlewafer rapid thermal oxidation of silicon process is used as the experimental platform. Response surface methodology consisting of design of experiments and regression techniques was used to construct the models. Results show that spatial uniformity metric with rational data subgrouping is needed to provide a more complete picture on the thickness uniformity. With different subgroupings of the oxide thickness data, we can offer better strategies for process optimization.

\section{INTRODUCTION}

Spatial uniformity is an important issue in semiconductor manufacturing processes, especially when the feature size is getting smaller and the wafer size is getting larger. It generally presents challenges in modeling, optimization, and control. In the literature, Taguchi has treated variation reduction as a pure robustness problem and minimized its value through parameter design [1]. Others have modeled the variation more specifically using the regression techniques. In particular, the Single Response Surface and Multiple Response Surfaces methods are discussed and compared [2][3]. In this paper, we use Response Surface Method (RSM), which consists of statistical design of experiments and regression techniques. Although RSM is a well-known methodology in the statistical literature, in practice it is the rational subgrouping of data and the choice of response metric that make the applications and interpretations ineffective and difficult.

The goal of this paper is then to present the rational subgrouping methodology for the modeling and optimization of the wafer-level spatial uniformity. A single-wafer rapid thermal oxidation of silicon process is used as the experimental platform.

\section{RAPID THERMAL OXIDATION}

For the growth of gate dielectrics in ULSI, rapid thermal oxidation (RTO) of silicon is an alternative to the conventional furnace processing. When compared with the conventional furnace processing, RTO has the advantages of single-wafer processing, low thermal budget, shorter processing time, and easy integration into cluster tools. However, it also contains some potential disadvantages, such as inconsistent temperature measurement, lack of thorough knowledge of the process, process nonuniformity and control. To increase the manufacturability of the RTO process, we need to optimize the process through process modeling techniques and reduce the nonuniformity problem. The single-wafer RTO machine used in this research is illustrated in Figure 1.

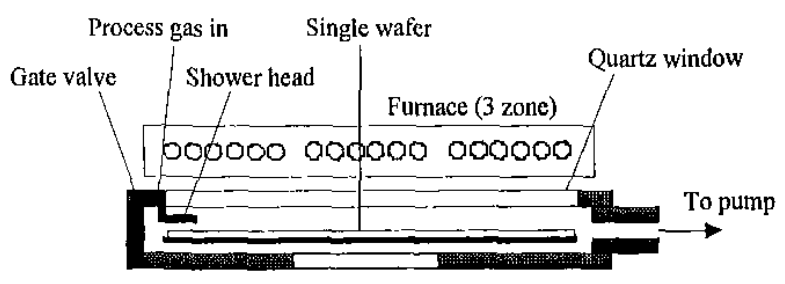

Figure 1: Single-wafer rapid thermal chamber

\section{EXPERIMENTAL DESIGN FOR TWO FACTORS}

In the RTO experiments, two process factors, processing time and temperature, were first used as the experimental factors in modeling the wafer-level spatial uniformity. An experimental ( 3 by 3 ) design with nine runs was performed. In each run more than 200 oxide thickness data were collected, Table 1 illustrates the experimental design.

\begin{tabular}{|c|c|c|c|c|c|}
\hline $\begin{array}{c}\text { Exp. } \\
\text { no }\end{array}$ & $\begin{array}{c}\text { Time } \\
(\mathrm{min})\end{array}$ & $\begin{array}{c}\text { Temp } \\
\left({ }^{\circ} \mathrm{C}\right)\end{array}$ & $\begin{array}{c}N U_{1} \\
(\%)\end{array}$ & $\begin{array}{c}N U_{2} \\
(\%)\end{array}$ & $\begin{array}{c}N U_{3} \\
(\%)\end{array}$ \\
\hline 1 & 1 & 900 & 9.85 & 6.85 & 7.37 \\
\hline 2 & 1 & 950 & 8.15 & 5.53 & 6.49 \\
\hline 3 & 1 & 1000 & 7.48 & 4.75 & 6.20 \\
\hline 4 & 2 & 900 & 7.73 & 6.06 & 5.03 \\
\hline 5 & 2 & 950 & 5.99 & 4.09 & 4.69 \\
\hline 6 & 2 & 1000 & 6.47 & 4.44 & 5.05 \\
\hline 7 & 4 & 900 & 6.58 & 4.67 & 4.93 \\
\hline 8 & 4 & 950 & 4.04 & 3.16 & 2.75 \\
\hline 9 & 4 & 1000 & 4.37 & 2.60 & 3.76 \\
\hline
\end{tabular}

Table 1: Experimental design and nonuniformity values

In the traditional modeling approach, we would calculate the wafer-level nonuniformity using the metric in (1), in which $\bar{x}$ is the mean of all the thickness data on each wafer, and $s$ is 
the estimated standard deviation (Figure 2a). With the nine nonuniformity values (Table 1 ), a second-order model that correlates the wafer-level nonuniformity to the two factors are constructed using the stepwise regression technique. Equation (2) shows the constructed model. For optimization purpose, we can perform canonical and ridge analysis on the response equation. It is usually useful to plot the contour plot to help identify the optimal point. Figure 3 a illustrates the plot.

$$
N U_{1}=\frac{s}{\bar{x}}=\frac{\sqrt{\frac{1}{n-1} \sum_{i=1}^{n}\left(x_{i}-\bar{x}\right)^{2}}}{\frac{1}{n} \sum_{i=1}^{n} x_{i}}
$$

$$
\begin{aligned}
N U_{1}= & 393.2355-0.7929(\mathrm{Temp}) \\
& +0.0004(\mathrm{Temp})^{2}-0.0012\left(\text { Temp }^{*} \text { Time }\right)
\end{aligned}
$$

With the same set of data, there is a second way to define the nonuniformity metric. As shown in Figure $2 \mathrm{~b}$, we divide the wafer into nine zones and calculate each zone's nonuniformity. The wafer-level nonuniformity is then calculated by using Equation (3). Again we can construct a second-order model as shown in (4). The contour plot is shown in Figure 3b.

$$
\begin{aligned}
N U_{2}= & \sqrt{\frac{\sum_{j=1}^{9}\left(s_{j} / \bar{x}_{j}\right)^{2}}{9}} \\
N U_{2}= & 251.7507-0.4999(\text { Temp }) \\
& +0.0003(\text { Temp })^{2}-0.0008(\text { Temp } * \text { Time })
\end{aligned}
$$

With the same set of data, there is a third way to define the nonuniformity metric. As shown in Figure 2c, we divide the wafer into nine zones and calculate each zone's average thickness. The wafer-level nonuniformity is then obtained by calculating the nonuniformity of these nine average thicknesses (Table 1). Equation (5) defines the metric. Again we can construct a second-order model as shown in (6). The contour plot is shown in Figure 3c.

$$
\begin{aligned}
& s^{\prime}=\sqrt{\frac{1}{9-1} \sum_{j=1}^{9}\left(\bar{x}_{j}-\bar{x}\right)^{2}} \\
& \bar{x}=\frac{1}{9} \sum_{j=1}^{9} \bar{x}_{j}=\frac{1}{n} \sum_{i=1}^{n} x_{i} \text { (if the same no. of points in all zones) }
\end{aligned}
$$

$$
N U_{3}=s^{\prime} / \bar{x}
$$

$$
\begin{array}{r}
\mathrm{NU}_{3}=9.1553+0.3836(\text { Time })^{2} \\
-0.0030\left(\text { Temp }{ }^{*} \text { Time }\right)
\end{array}
$$

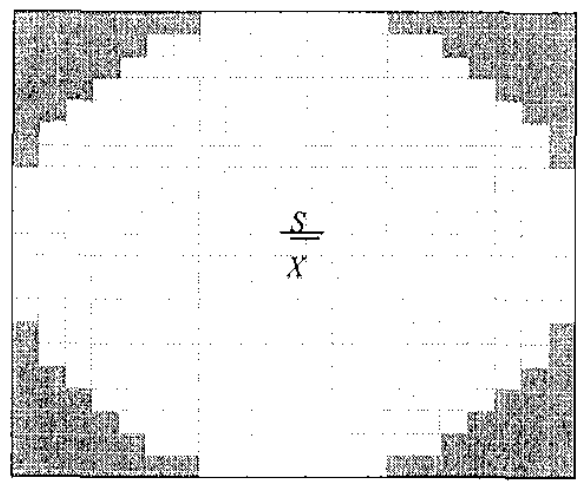

(a) $N U_{1}=s / \bar{x}$
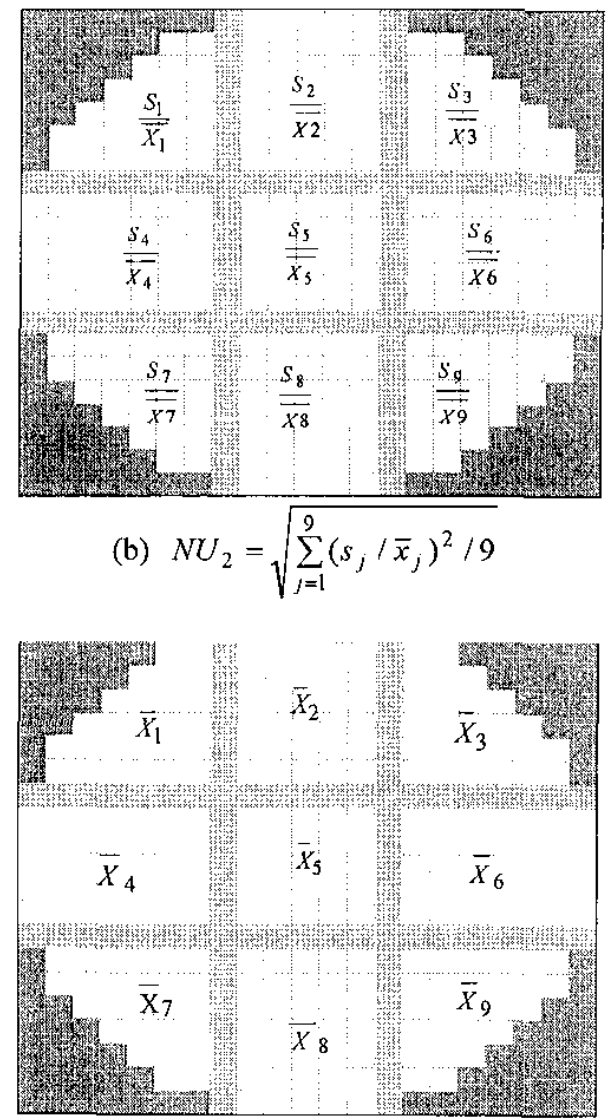

(c) $N U_{3}=s^{\prime} / \bar{x}$

Figure 2: Three ways to define the nonuniformity metrics

Our goal is to optimize the process by minimizing the nonuniformity. However, with three different metrics and their corresponding response surface plots (Figures $3 a-3 c$ ), we are led to very different optimization strategies. In fact, under certain assumptions it can be proved that the relationship between $N U_{1}, \quad N U_{2}$ and $N U_{3}$ can be approximated by the following equation: 


$$
\left(N U_{1}\right)^{2} \approx\left(N U_{2}\right)^{2}+\left(N U_{3}\right)^{2}
$$

The total nonuniformity of the surface $\left(N U_{1}\right)$ actually consists of two parts. The first term $\left(\mathrm{NU}_{2}\right)$ on the right hand side of (7) measures the surface roughness while the second term $\left(\mathrm{NU}_{3}\right)$ is a measure of the surface unevenness. For an even surface $\left(\vec{x}_{1}=\bar{x}_{2}=\cdots=\bar{x}\right)$, the second term becomes zero. Then, $N U_{1} \approx N U_{2}$. For a surface with a slope (e.g. $\left.\bar{x}_{1} \leq \bar{x}_{2} \leq \bar{x}_{3}\right), N U_{1} \geq N U_{2}$.

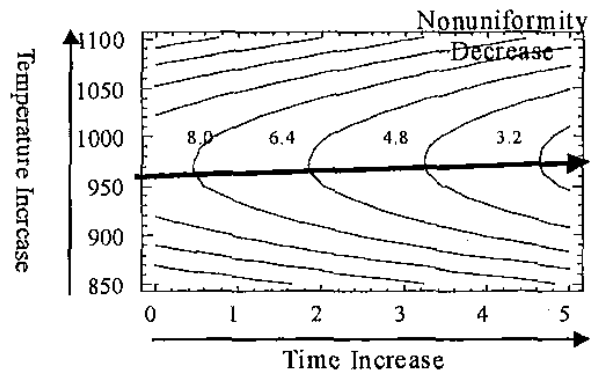

(a) Contour plot based on $N U_{1}$

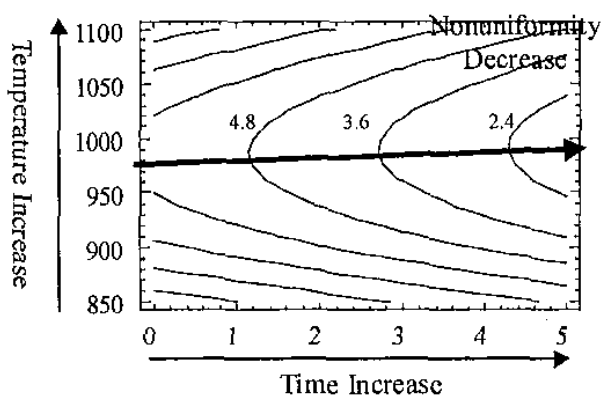

(b) Contour plot based on $\mathrm{NU}_{2}$

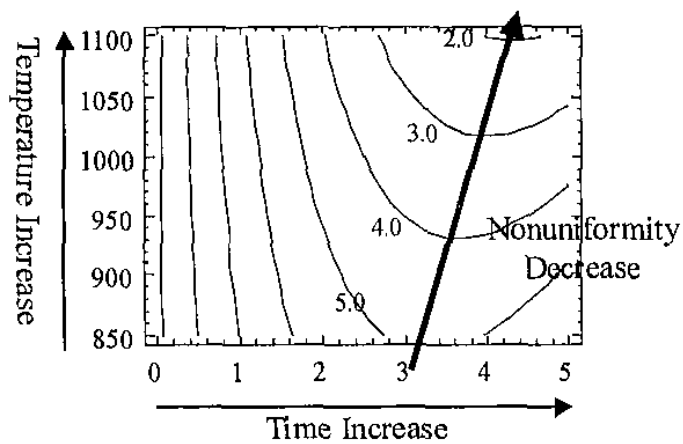

(c) Contour plot based on $\mathrm{NU}_{3}$

Figure 3: Response surface contour plots

Figure $3 b$ reveals that a longer processing time can reduce the surface roughness while temperature should be set around $975^{\circ} \mathrm{C}$ to minimize the roughness. It can be also observed from Figure $3 \mathrm{c}$ that temperature does not have a significant effect on the surface evenness when processing time is less than three minutes. For processing time around three to four minutes, the higher the temperature the better the surface evenness. Since processing time has significant effects on both the roughness and the evenness, it results in a steeper ridge and a governing direction on the response surface of the total nonuniformity $\left(N U_{1}\right)$ as shown in Figure 3a.

In summary, when we optimize the process to minimize the thickness nonuniformity, the usual metric in (1) is not sufficient. Better strategies will be to minimize the roughness and the evenness separately. In general, the evenness is usually optimized through a better process or equipment design while the roughness can be minimized by refining the process recipe.

\section{EXPERIMENTAL DESIGN FOR FOUR FACTORS}

To further study the effect of rational subgrouping on modeling wafer-level nonuniformity, four-factor design of experiments were performed. Taguchi L9 experimental design [1] was used to study four factors: processing time, temperature, pressure and flow rate. In each run more than 200 oxide thickness data were collected. Table 2 illustrates the experimental design.

\begin{tabular}{|c|c|c|c|c|c|c|c|}
\hline $\begin{array}{c}\text { Exp. } \\
\text { no }\end{array}$ & $\begin{array}{c}\text { Time } \\
(\mathrm{min})\end{array}$ & $\begin{array}{c}\text { Temp } \\
\left({ }^{\circ} \mathrm{C}\right)\end{array}$ & $\begin{array}{c}\text { Press } \\
(\mathrm{mbar})\end{array}$ & $\begin{array}{c}\text { Flow } \\
(\mathrm{sccm})\end{array}$ & $\begin{array}{c}\mathrm{NU}_{1} \\
(\%)\end{array}$ & $\begin{array}{c}N U_{2} \\
(\%)\end{array}$ & $\begin{array}{c}\mathrm{NU} \\
(\%)\end{array}$ \\
\hline 1 & 0.5 & 900 & 500 & 400 & 8.74 & 4.86 & 7.57 \\
\hline 2 & 0.5 & 950 & 250 & 500 & 7.59 & 6.76 & 4.02 \\
\hline 3 & 0.5 & 1000 & 375 & 300 & 9.07 & 6.78 & 6.36 \\
\hline 4 & 1 & 900 & 250 & 300 & 20.42 & 16.30 & 12.23 \\
\hline 5 & 1 & 950 & 375 & 400 & 10.38 & 4.86 & 9.65 \\
\hline 6 & 1 & 1000 & 500 & 500 & 7.48 & 4.75 & 6.19 \\
\hline 7 & 2 & 900 & 375 & 500 & 9.75 & 5.09 & 8.78 \\
\hline 8 & 2 & 950 & 500 & 300 & 15.33 & 8.60 & 12.83 \\
\hline 9 & 2 & 1000 & 250 & 400 & 16.45 & 10.90 & 12.71 \\
\hline
\end{tabular}

Table 2: L9 design for four factors and nonuniformity values

Using the same metrics as defined in Equations (1), (3), and (5), nonuniformity values are calculated and summarized in Table 2. We then calculate the main effects of each factor and plot the effect plots [1] in Figure 4. Here in Figure 4, processing time is indicated by $\mathrm{A}$, temperature by $\mathrm{B}$, pressure by $\mathrm{C}$ and flow rate by $\mathrm{D}$. The corresponding ANOVA tables are also listed in Tables 3,4, and 5. Values in the graded areas represent the pooled errors.

In this experiment, we confirm the following observations from the first experiment:

- For processing time less than three minutes, temperature does not have a significant effect on the surface evenness (Figure $4 \mathrm{c}$, effect of $\mathrm{B}$ ).

- To minimize the roughness, temperature should be set around $950^{\circ}-975^{\circ}$ (Figure $4 \mathrm{~b}$, effect of $B$ ).

- For processing time lasting for less than three minutes, its effect is especially strong on the evenness and is also significant on the roughness.

- The effect on the total nonuniformity appears to be the sum of the effects on the roughness and unevenness. 
Additional observations can be summarized as follows:

- For the total nonuniformity, processing time, pressure, and flow rate are all significant factors.

- To minimize the nonuniformity, pressure should be set around $375 \mathrm{mbar}$.

- Flow rate seems to have negative effects on both the evenness and the roughness.

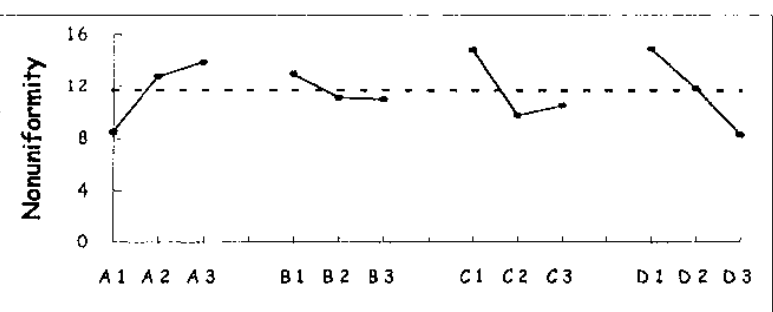

(a) Effect plot based on $\mathrm{NU}_{1}$

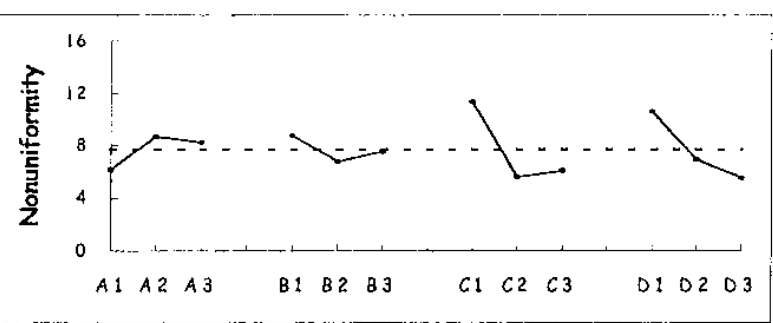

(b) Effect plot based on $\mathrm{NU}_{2}$

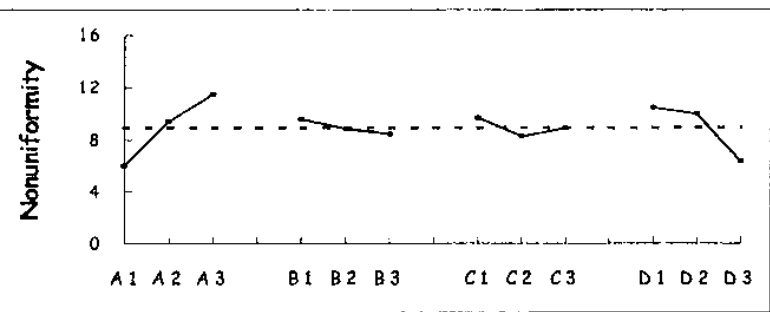

(c) Effect plot based on $\mathrm{NU}_{3}$

Figure 4: Effect plots for the $\mathrm{L}_{9}$ experiment

\begin{tabular}{|l|c|c|c|c|}
\hline \multicolumn{1}{|c|}{ Factor } & $\begin{array}{c}\text { Degrees of } \\
\text { freedom }\end{array}$ & $\begin{array}{c}\text { Sum of } \\
\text { Squares }\end{array}$ & $\begin{array}{c}\text { Mean } \\
\text { Square }\end{array}$ & F \\
\hline A. Time & 2 & 48.50 & 24.25 & 6.56 \\
\hline B. Temperature & 2 & 7440 & 3.70 & \\
\hline C. Pressure & 2 & 45.08 & 22.54 & 6.09 \\
\hline D. Flow rate & 2 & 66.73 & 33.36 & 9.02 \\
\hline Error & 0 & 0.00 & & \\
\hline Total & 8 & 167.71 & & \\
\hline (Erron) & 2 & 740 & 3.90 & \\
\hline
\end{tabular}

Table 3: ANOVA table for $N U_{1}$

\begin{tabular}{|c|c|c|c|c|}
\hline Factor & $\begin{array}{c}\text { Degrees of } \\
\text { freedom }\end{array}$ & $\begin{array}{l}\text { Sum of } \\
\text { Squares }\end{array}$ & $\begin{array}{c}\text { Mean } \\
\text { Square }\end{array}$ & $\mathrm{F}$ \\
\hline A. Time & 2 & 1082 & 5.41 & \\
\hline B. Temperature & 2 & 6.25 & 3.12 & \\
\hline C. Pressure & 2 & 61.37 & 30.69 & 7.19 \\
\hline D. Flow Rate & 2 & 40.82 & 20.41 & 4.78 \\
\hline Error & 0 & 0.00 & & \\
\hline Total & 8 & 119.26 & & \\
\hline (Error) & 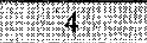 & 1706 & WI & \\
\hline
\end{tabular}

Table 4: ANOVA table for $\mathrm{NU}_{2}$

\begin{tabular}{|c|c|c|c|c|}
\hline Factor & $\begin{array}{c}\text { Degrees of } \\
\text { freedom }\end{array}$ & $\begin{array}{l}\text { Sum of } \\
\text { Squares }\end{array}$ & $\begin{array}{c}\text { Mean } \\
\text { Square }\end{array}$ & $\mathrm{F}$ \\
\hline A. Time & 2 & 45.45 & 22.73 & 19.04 \\
\hline B. Temperature & 2 & 1.88 & 0.94 & \\
\hline C. Pressure & 2 & 2.89 & 1.45 & \\
\hline D. Flow rate & 2 & 30.69 & 15.35 & 12.86 \\
\hline Error & 0 & 0.00 & & \\
\hline Total & 8 & 80.92 & & \\
\hline$($ Errot) & 4 & 477 . & 19 & 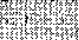 \\
\hline
\end{tabular}

Table 5: ANOVA table for $\mathrm{NU}_{3}$

\section{CONCLUSIONS}

In conclusion, rational subgrouping will allow us to understand the wafer-level nonuniformity with two distinct features. One is the surface roughness and the other is the surface unevenness. Very different actions may be needed to improve the two different features. We also find in our study that it is dangerous to use the usual nonuniformity metric alone. Nonuniformity metrics with rational data subgrouping will be needed to provide a more complete picture on the wafer-level nonuniformity and better strategies to optimize the process.

\section{REFERENCES}

[1]. M. Phadke, Quality Engineering Using Robust Design, Prentice-Hall, 1989.

[2]. R. Guo and E. Sachs, "Modeling, Optimiztaion and Control of Spatial Uniformaity in Manufacturing Processes," IEEE Transactions on Semiconductor Manufacturing, vol.6, no.1, 1993.

[3]. T. Smith, B. Goodlin, and D. Boning, "Bias and Variance in Single and Multiple Response Surface Modeling," $3^{\text {rd }}$ International Workshop on Statistical Metrology, Hawaii, 1996. 